\title{
POLYGENIC SYSTEMS CONTROLLING THE EXPRESSION OF MAJOR MUTANT GENES WHICH AFFECT CHAETA NUMBER IN DROSOPHILA MELANOGASTER
}

\author{
BETTY COCKS \\ Welsh Plant Breeding Station, Aberystwyth
}

Received I5.i.53

\section{INTRODUCTION}

Continuous variation has been shown to be under the control of both genetic and environmental factors. In so far as it is genetically determined it can be accounted for by assuming the degree of expression of a character to be under the control of a number of genes of small, similar and supplementary effect. All such genes affecting any one character constitute a polygenic system, the members of which act to increase or decrease the manifestation of the character. Natural selection establishes balance in such polygenic systems by adjustment of the proportions and intra-chromosome arrangement of its members (Mather, 1942) so that the expression of the character is more or less stable and approaches the optimum for the existing environmental conditions. The polygenic systems operative in wild-type individuals will have been exposed to the continuous action of natural selection and so have become balanced in this way.

Characters showing polygenic variability may also be influenced by major genes. Since major mutants are rare in the wild, the polygenes affecting a character in their presence will not have been exposed to the balancing action of natural selection as have those of the wild type, unless the same polygenic systems are effective in the same way in the presence of either allelomorph. If this is the case, balance established in wild-type individuals will be displayed equally in the mutants, whereas if some or all members of the polygenic systems operative in the two classes differ, this parallelism will not be expected to occur.

An experiment to compare the polygenic systems operative in mutants and non-mutants was carried out by Haskell (1943). He had available four lines of Drosophila melanogaster with different mean numbers of abdominal chaetæ, the number of chaetæ being under polygenic control. Into each line he introduced by back-crossing the gene scute (sc), which approximately halves the number of abdominal chaetæ; this technique permitted the comparison of mutant and non-mutant brothers in each generation. If the polygenes governing the number of abdominal chaetæ are the same in mutants and non-mutants, though the gene $s c$ will reduce the absolute number of abdominal chaetæ, the relative values of the line means after 
back-crossing should not be affected; while if different polygenes are operating, the relative values of the line means in the two groups will be expected to differ. Haskell found that the mean numbers of abdominal chaetæ in scute males did not parallel those of non-scute males, thus showing that the polygenes controlling chaeta number in the two groups are not the same or do not have the same action in scute and non-scute flies. This was supported by evidence of greater differences in variability of chaeta number from one generation to the next in the scute flies, indicating that, as might be expected from the lack of opportunity for natural selection, the polygenic systems are less balanced here than in non-scute flies.

Haskell's results were derived by the use of a single major gene in only four lines and his families were not very large. This same approach has been used here on a larger scale with three major mutant genes. In addition to establishing whether there was any difference between the polygenic systems operating in mutants and non-mutants, it was hoped to compare the extent of any such difference among the three mutants and also between the polygenic systems controlling two similar characters, which may be both affected by the three major mutant genes.

\section{EXPERIMENTAL METHOD}

The characters chosen for investigation were the pooled numbers of sternopleural chaetæ on the right and left sides and the pooled numbers of abdominal chaetæe on the fourth and fifth abdominal segments. These are the terminal chaeta-bearing segments in the male; in the female the sixth segment also bears chaetx on the ventral surface.

Ten wild-type lines of $D$. melanogaster were available, covering a wide range in their mean numbers of sternopleural and abdominal chaetre. Of the lines, two were the inbred lines Oregon (Or.) and Samarkand (Sk.) which had been maintained by single pair brothersister mating for 232 and II 7 generations respectively when this work was begun. Six of the lines (lines 2, 3, 6, 7, 8 and 9) were among those produced by Mather and Harrison (1949) in their selection experiments. The mean chaeta numbers of the lines, obtained from counts made at intervals during the course of the experiments on stock cultures kept under conditions similar to those of the experimental flies, are given in table $\mathrm{I}$.

These six lines had been maintained in mass culture since the end of the selection experiments, a period of about three years. Since artificial selection had not been practised on the inbred lines and had been relaxed on the other six lines for three years, these eight lines will have been subject to natural selection in the culture bottle for a long period - 30 to 40 generations for the selected lines. During this time the polygenic systems responsible for chaeta number will, 
in so far as variation is still present in them, have been subject to the balancing action of natural selection.

Two further lines (line $\mathrm{H}$ and line $\mathrm{L}$ ) were produced by selection for increased and decreased numbers of sternopleural chaetæ, selection commencing in the $\mathrm{F}_{2}$ of a cross between the Oregon and Samarkand lines. Selection was at a ro per cent. level for the first eight generations, the two male and female parents being taken from twenty on which

TABLE I

Mean numbers of sternopleural and abdominal chate in the experimental lines

\begin{tabular}{|c|c|c|}
\hline \multirow{2}{*}{ Line } & \multicolumn{2}{|c|}{ Mean chaeta number } \\
\hline & Sternopleurals & Abdominals \\
\hline Sk. & $\left.\begin{array}{cc}q & 19 \cdot 20 \\
o & 18 \cdot 75\end{array}\right\} 18.97$ & $\left.\begin{array}{l}37 \cdot 81 \\
34 \cdot 90\end{array}\right\} 3^{6 \cdot 35}$ \\
\hline Or. & 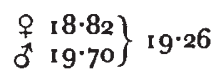 & $\left.\begin{array}{l}42 \cdot 59 \\
38 \cdot 93\end{array}\right\} 4^{0 \cdot 76}$ \\
\hline 2 & $\left.\begin{array}{ll}\text { ㅇ } & 22 \cdot 00 \\
\text { o } & 21 \cdot 80\end{array}\right\} 21 \cdot 90$ & $\left.\begin{array}{l}35 \cdot 15 \\
32 \cdot 12\end{array}\right\} 33 \cdot 63$ \\
\hline 3 & $\left.\begin{array}{ll}\stackrel{9}{q} & 17 \cdot 5^{8} \\
o & 17 \cdot 5^{1}\end{array}\right\}$ I $7 \cdot 54$ & $\left.\begin{array}{l}44^{\cdot 1} 8 \\
4^{1} \cdot 22\end{array}\right\} 4^{1 \cdot 32}$ \\
\hline 6 & 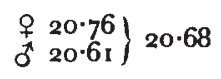 & $\begin{array}{l}67 \cdot 07 \\
55 \cdot 66 j 6 r \cdot 36\end{array}$ \\
\hline 7 & $\left.\begin{array}{cc}o & 17 \cdot 75 \\
o & 17 \cdot 20\end{array}\right\} 17 \cdot 47$ & $\left.\begin{array}{l}52 \cdot 75 \\
45 \cdot 36\end{array}\right\} 49 \cdot 05$ \\
\hline 8 & $\left.\begin{array}{cc}\stackrel{9}{1} & 18 \cdot 51 \\
o & 17 \cdot 83\end{array}\right\} 18 \cdot 17$ & $\left.\begin{array}{l}56 \cdot 34 \\
46 \cdot 25\end{array}\right\} 5^{1 \cdot 29}$ \\
\hline 9 & $\left.\begin{array}{ll}q & 21 \cdot 64 \\
o & 20 \cdot 16\end{array}\right\} 20 \cdot 90$ & $\left.\begin{array}{l}54 \cdot 7 r \\
4^{8} \cdot 5^{2}\end{array}\right\} 5^{I \cdot 6 r}$ \\
\hline H. & $\left.\begin{array}{ll}q & 25 \cdot 60 \\
o & 24 \cdot 70\end{array}\right\} 25 \cdot 15$ & $\begin{array}{l}\cdots \\
\cdots\end{array}$ \\
\hline L. & $\left.\begin{array}{cc}q & 16 \cdot 70 \\
o & 15 \cdot 50\end{array}\right\}$ 16.10 & $\begin{array}{l}\cdots \\
\cdots\end{array}$ \\
\hline
\end{tabular}

chaeta counts were made. From then on the lines were maintained in mass culture. Selection was continued at a 50 per cent. level, the ten male and female parents being taken from twenty counted. The polygenic systems responsible for chaeta number in these two lines had thus not been exposed to the action of natural selection as had those of the other eight lines, and comparisons of the variability in the two groups may not be strictly valid.

The major mutant genes investigated were Sternopleural $(S p)$, Hairless $(H)$, and scute $(s c)$; of these the former two are autosomal 
dominants, both lethal when homozygous and scute is a sex-linked recessive. Details of the positions and main phenotypic effects of the mutant genes will be found in Bridges and Brehme (1944). Their effects on the sternopleural and abdominal chaetæ are shown in fig. I.

The following methods of culture were used throughout the experiments. The flies were mated in tubes for two days, single pair matings being used in all cases. The pairs were then transferred to half-pint milk bottles, which were kept in the incubator at $25^{\circ} \mathrm{C}$.

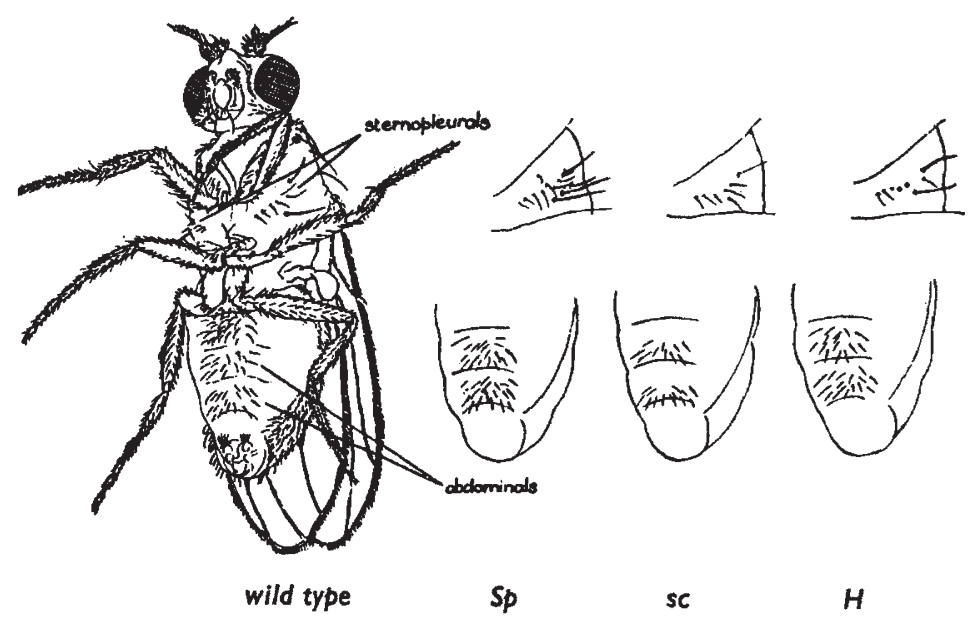

FrG. 1. - The effect of the major mutant genes $S p$, sc and $H$ on abdominal and sternopleural chaeta number.

The bottles of any one generation were thoroughly mixed before placing in the incubator to ensure that any temperature effects on chaeta number due to position would be at random among the different lines. The parents were shaken out from these bottles into a second set after two days, the second bottles being used in the event of failure of any of the first set to produce progeny. After emergence the flies on which counts were to be made were removed morning and evening, the sexes sorted and stored separately until counting.

The sternopleural and abdominal chaetæ were counted on twenty individuals of each sex in some generations, in others on ten; in a few cases less than this number were used where the bottles did not yield the requisite number of flies.

\section{CROSSING TECHNIQUE}

Each of the three major mutant genes was introduced by backcrossing into certain of the test lines in such a way that mutant and non-mutant sibs were available for comparison in each generation. 
The crossing technique used for sc differed from that for the two autosomal dominants and will be described separately.

The autosomal dominants. Sternopleural and Hairless.-The gene $S p$ was obtained from the stock $\frac{S p B l L}{C y}$ and introduced into each line individually by the necessary crosses. $H$ was obtained from the stock $\frac{C l B}{+} ; \frac{C y L}{P m} ; \frac{H}{S b}$, and introduced into a wild-type background prior to use in these experiments, this stock, wild-type except for $H$, being used for the crosses with the test lines.

Matings were made between virgin females of the stocks containing the dominant mutant gene to be investigated and males of the test lines. Heterozygous mutant females, from the resulting $F_{1}$, were back-crossed to line males giving four classes of progeny, mutant and non-mutant males and females, again in the next generation. This was continued for up to 25 generations in the $S p$ experiment, I I generations in the $H$ experiment. Counts were made on chaeta number in all four classes, the females used for mating being the first three mutant females counted. Three matings were made for each line in each generation to allow for losses, the culture to be counted being taken at random from the three.

The sex-linked recessive scute.--This gene was obtained from the stock $\frac{C l B}{s c v f c a r}$ and was introduced into a wild-type background by crossing and selection of the requisite recombinant type. The first cross made in this case was between line females and sc males, giving all heterozygous scute females (and wild-type males) in the $\mathrm{F}_{\mathbf{1}}$. Single pair matings were then made between these females and line males. In the next generation the four classes of progeny produced were $+1+$ and $+/ s c$ females, which were indistinguishable phenotypically, and + and sc males. Seven matings were made between line males and the phenotypically wild-type females. At emergence these were inspected for the presence of scute males in the progeny, and the culture on which counts were made was taken at random from those in which such males were found.

As it was possible to make comparisons only between mutant and non-mutant males in this experiment, counts were confined to these two classes.

Following the repeated back-crosses of the mutant females to line males, the genotypes of the experimental flies will approach more closely the genotypes of the test lines in each succeeding generation, polygenes brought in from the mutant stocks being progressively eliminated. The rate of elimination will, of course, differ for genes linked and unlinked with the major mutant. In the $n$th generation after crossing the mutant and non-mutant flies, the chance of persistence of a gene of the mutant stock will be $(I-c)^{n-1}$, where $c$ is the probability 
of recombination between this gene and the major mutant which is kept heterozygous (Bartlett and Haldane, 1935). For unlinked genes and linked genes with a recombination value of $5^{\circ}$ per cent. this will reduce to $\frac{1}{2}^{n-1}$; for genes more tightly linked it will be less, depending on the closeness of linkage.

Thus the genetic background of mutant and non-mutant sibs will be very similar after the first few generations of back-crossing, with the exception of genes very closely linked to the major mutant, and will be similar also to that in the corresponding test lines. By the fifth back-cross, 98.4 per cent. similarity of genes of experimental and test lines will be expected for genes giving 50 per cent. recombination with the mutant gene; this value will be less for genes giving less than 50 per cent. recombination. (A possible instance of the effect of genes closely linked to the major mutant, on abdominal chaeta number in $S p$ flies is discussed later.)

\section{RESULTS \\ (i) The counts}

From counts made of sternopleural and abdominal chaeta number a mean value was obtained for mutants and non-mutants in each generation counted. For each of the four series (i.e. mutant and non-mutant abdominals and sternopleurals) in each line, an overall mean was calculated by averaging the generation means of the fifth back-cross onwards. These overall means and their standard errors are recorded in tables 2A $(S p)$, 2B $(s c)$ and 2C $(H)$.

It was decided to omit generations prior to the fifth back-cross (B5) in computing these overall means, since the differences between generation means were considerably more marked in the earlier generations. By $\mathrm{B}_{5}$ the genotypes of the experimental lines should be very similar to those of the corresponding test lines.

The means of the non-mutant experimental flies show little difference from those of the stock cultures kept under similar conditions (table I). There is an apparent exception to this in the abdominals of line 9. Abdominal chaeta number in this line fell by about ${ }_{5}$ chaeta in the course of the experiments, from a mean of about 65 chaeta to one of 50 in the last count made. Thus the means of the non-mutant experimental flies of line 9 in the three experiments, while they are similar to the means of counts made on the stock during the individual experiments, do not cos respond with the value obtained by pooling the results of all three. The average magnitude of the effect of the major mutants on chaeta number can be seen from table 2.

A comparison of the individual mutant and non-mutant means brings out the following points. In the $S p$ mutants the abdominal chaeta number is slightly below and the sternopleural chaeta number almost double that of the corresponding non-mutant series, though 
TABLE 2

Mean chaeta number and its standard error in mutant and non-mutant fies

TABLE 2A. - Sp experiment

\begin{tabular}{|c|c|c|c|c|}
\hline \multirow{2}{*}{ Line } & \multicolumn{2}{|c|}{ Abdominals } & \multicolumn{2}{|c|}{ Sternopleurals } \\
\hline & Non-mutants $(\bar{x})$ & Mutants $S p(\bar{y})$ & Non-mutants $(\bar{x})$ & Mutants $S p(\bar{y})$ \\
\hline $\begin{array}{l}2 \\
3 \\
6 \\
7 \\
8 \\
9 \\
S k \\
O r \\
H \\
L\end{array}$ & $\begin{array}{l}34 \cdot 63 \pm 0.36 \\
42 \cdot 63 \pm 0.22 \\
62 \cdot 91 \pm 0.57 \\
51 \cdot 41 \pm 0.36 \\
51 \cdot 88 \pm 0.47 \\
59 \cdot 14 \pm 1 \cdot 34 \\
35 \cdot 79 \pm 0.33 \\
41 \cdot 54 \pm 0.17 \\
35 \cdot 47 \pm 0.25 \\
36 \cdot 19 \pm 0.33\end{array}$ & $\begin{array}{l}32 \cdot 20 \pm 0.34 \\
41 \cdot 91 \pm 0.21 \\
60 \cdot 19 \pm 0.98 \\
47 \cdot 06 \pm 1 \cdot 02 \\
46 \cdot 43 \pm 0.40 \\
57 \cdot 63 \pm 1 \cdot 11 \\
31 \cdot 85 \pm 0.43 \\
39 \cdot 85 \pm 0.26 \\
34.49 \pm 0.64 \\
36.01 \pm 0.31\end{array}$ & $\begin{array}{l}22.23 \pm 0.27 \\
17.66 \pm 0.10 \\
19.69 \pm 0.20 \\
17.65 \pm 0.13 \\
17.35 \pm 0.19 \\
19.56 \pm 0.50 \\
19.80 \pm 0.22 \\
19.56 \pm 0.18 \\
27.81 \pm 0.33 \\
15.96 \pm 0.16\end{array}$ & $\begin{array}{l}37.87 \pm 0.68 \\
28.34 \pm 0.38 \\
33.33 \pm 0.40 \\
30.27 \pm 0.25 \\
31.44 \pm 0.26 \\
33.68 \pm 0.57 \\
33.40 \pm 0.74 \\
31.96 \pm 0.78 \\
49.41 \pm 0.55 \\
25.99 \pm 0.68\end{array}$ \\
\hline $\begin{array}{l}\text { Me } \\
\text { Dif }\end{array}$ & $\begin{array}{l}\text { ce } \quad 45 \cdot 12 \\
\text { nt mean }-n\end{array}$ & $\begin{array}{l}6 \quad 4^{2 \cdot 76} \\
\text { Int mean) }\end{array}$ & $19 \cdot 73$ & $33 \cdot 57$ \\
\hline
\end{tabular}

TABLE 2B.- $-s c$ experiment

\begin{tabular}{|c|c|c|c|c|}
\hline \multirow{2}{*}{ Line } & \multicolumn{2}{|c|}{ Abdominals } & \multicolumn{2}{|c|}{ Sternopleurals } \\
\hline & Non-mutants $(\bar{x})$ & Mutants $s c(\bar{y})$ & Non-mutants $(\bar{x})$ & Mutants sc $(\bar{y})$ \\
\hline $\begin{array}{l}2 \\
3 \\
6 \\
7 \\
8 \\
9 \\
S k \\
\text { Or }\end{array}$ & $\begin{array}{l}31 \cdot 94 \pm 0 \cdot 62 \\
40 \cdot 72 \pm 0 \cdot 23 \\
57 \cdot 41 \pm 0 \cdot 73 \\
47 \cdot 20 \pm 0 \cdot 36 \\
47 \cdot 16 \pm 0 \cdot 41 \\
49 \cdot 27 \pm 1 \cdot 51 \\
34 \cdot 63 \pm 0 \cdot 24 \\
39 \cdot 87 \pm 0 \cdot 39\end{array}$ & $\begin{array}{l}11 \cdot 19 \pm 0.53 \\
20.55 \pm 0.32 \\
25.50 \pm 0.34 \\
22 \cdot 02 \pm 0.53 \\
23 \cdot 00 \pm 0.38 \\
21 \cdot 04 \pm 0.69 \\
15.25 \pm 0.22 \\
19.51 \pm 0.15\end{array}$ & $\begin{array}{l}23.14 \pm 0.25 \\
17.67 \pm 0.24 \\
19.28 \pm 0.23 \\
18.00 \pm 0.15 \\
17.27 \pm 0.17 \\
20.74 \pm 0.30 \\
19.46 \pm 0.21 \\
19.94 \pm 0.28\end{array}$ & $\begin{array}{l}19.17 \pm 0.17 \\
15.53 \pm 0.23 \\
20.04 \pm 0.54 \\
17.29 \pm 0.10 \\
17.32 \pm 0.16 \\
19.47 \pm 0.42 \\
17.35 \pm 0.25 \\
18.47 \pm 0.35\end{array}$ \\
\hline
\end{tabular}

$\begin{array}{lllllll}\text { Mean } & 43.52 & -23.76 & 19.76 & 19.44 & & 18 \cdot 08 \\ \text { Difference } & & -1 \cdot 36 & \end{array}$

TABLE 2C.- $H$ experiment

\begin{tabular}{|c|c|c|c|c|}
\hline \multirow{2}{*}{ Line } & \multicolumn{2}{|c|}{ Abdominals } & \multicolumn{2}{|c|}{ Sternopleurals } \\
\hline & Non-mutants $(\bar{x})$ & Mutants $H(\bar{y})$ & Non-mutants $(\bar{x})$ & Mutants $H(\bar{y})$ \\
\hline $\begin{array}{l}2 \\
3 \\
6 \\
7 \\
8 \\
9 \\
O r \\
H \\
L\end{array}$ & $\begin{array}{l}33 \cdot 85 \pm 0 \cdot 28 \\
43 \cdot 29 \pm 0.30 \\
62 \cdot 94 \pm 1 \cdot 07 \\
51 \cdot 65 \pm 0 \cdot 47 \\
53 \cdot 57 \pm 0 \cdot 51 \\
47 \cdot 79 \pm 1 \cdot 56 \\
41 \cdot 54 \pm 0 \cdot 97 \\
34 \cdot 81 \pm 0.37 \\
35 \cdot 26 \pm 0 \cdot 47\end{array}$ & $\begin{array}{l}27 \cdot 59 \pm 0.35 \\
33 \cdot 50 \pm 0.25 \\
43.31 \pm 0.31 \\
38.88 \pm 0.17 \\
40.03 \pm 0.36 \\
34 \cdot 64 \pm 0.39 \\
31 \cdot 93 \pm 0.77 \\
27 \cdot 28 \pm 0.43 \\
27.58 \pm 0.42\end{array}$ & $\begin{array}{l}22.59 \pm 0.31 \\
18.01 \pm 0.13 \\
19.69 \pm 0.22 \\
18.03 \pm 0.25 \\
17.34 \pm 0.11 \\
19.92 \pm 0.25 \\
19.73 \pm 0.10 \\
28.41 \pm 0.27 \\
15.68 \pm 0.21\end{array}$ & $\begin{array}{l}17.28 \pm 0.31 \\
10.93 \pm 0.19 \\
11.52 \pm 0.46 \\
12.14 \pm 0.21 \\
11.58 \pm 0.22 \\
13.07 \pm 0.55 \\
12.41 \pm 0.43 \\
21.33 \pm 0.19 \\
12.52 \pm 0.17\end{array}$ \\
\hline $\begin{array}{l}\text { Mea } \\
\text { Diffe }\end{array}$ & $44 \cdot 97$ & $33 \cdot 86$ & $19 \cdot 93$ & 13.81 \\
\hline
\end{tabular}


there is no apparent change in the order of the line means for either character. The sc mutants have abdominal chaeta numbers considerably lower than their non-mutant brothers, and although the order of the lines is unchanged, the differences between the high lines are much smaller in mutants than in non-mutants. There is in general a slight reduction in the number of sternopleural chaetæ in $s c$ mutants, the relative positions of the lines showing considerable differences from the non-mutant series, a change in the positions of lines 2 and 6 being particularly apparent.

In the $H$ mutants both abdominal and sternopleural chaeta numbers are reduced. For abdominals the order of the line means is very similar in mutants and non-mutants, but for sternopleurals there are changes in the relative positions of certain lines, notably lines 6 and $\mathrm{L}$.

\section{(ii) Seriation}

The relative order in magnitude or seriation of the line means depends on the action of the polygenic systems. If the same polygenes are operating in mutant and non-mutant sibs, and if these have the same action in each, the relative order of the line means in mutants and non-mutants should be the same. If the polygenes differ in action in the two groups or if distinct polygenic systems are operating, the seriation of mutants and non-mutants may differ. The extent of differences in seriation will then give an indication of the extent of the differences between the operative polygenic systems of the two groups.

Comparison of the seriation was approached by the application of the regiession analysis to mutant and non-mutant means. Using the values of table 2, scatter diagrams were plotted of mutant mean $(\bar{y})$ against nun-mutant mean $(\bar{x})$ (Figs. $2 a$ to $2 f$ ). If there were complete correlation between the mutant $(y)$ and non-mutant $(x)$ values, any increase in $y$ being proportional to an increase in $x$, an exact linear relationship would be obtained, and a straight line could be found to fit to these points, within the limits of sampling error. Where such an exact linear relationship does not exist, the points will not lie on a straight line but a "best-fitting" straight line can be found and will be that which minimises the sums of squares of the deviations of the $y$ values from their expectations, as found from the regression line. The extent to which the relation between the $x$ and $y$ values deviates from linearity will be given by the part of the total sum of squares which is attributable to the deviations of the $y$ values from the best-fitting straight line. The remainder of the sum of squares of $y$, which is removed by regression on $x,\left(\frac{\mathrm{S}^{2} y(x-\bar{x})}{\mathrm{S}(x-\bar{x})^{2}}\right)$, will indicate the extent of the similarity in seriation of mutant and non-mutant means. This value expressed as a percentage of the total sum of squares of $y$ will be termed the "percentage sum of 

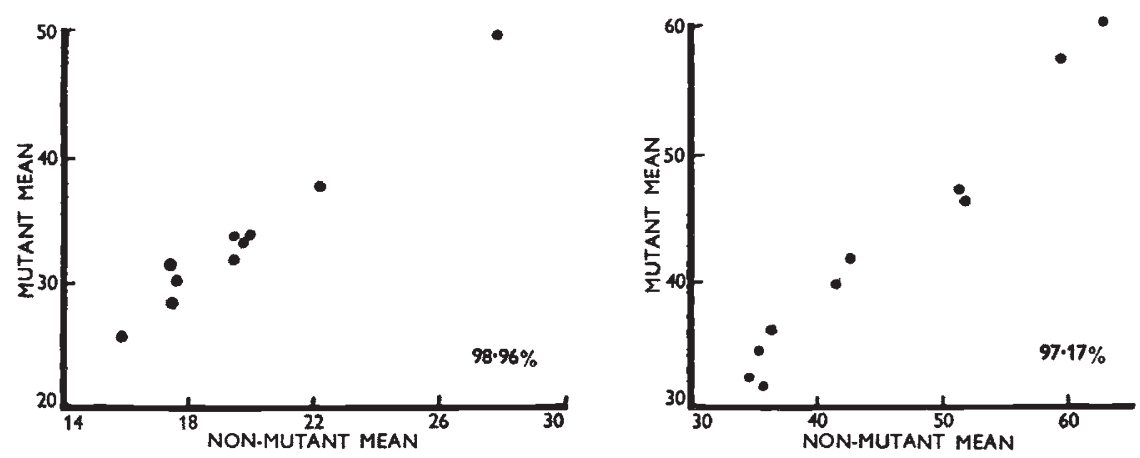

FIG. 2a.-Sternopleural chaetæ. Sp experiment. Frg. 2d.-Abdominal chaetæ. Sp experiment.
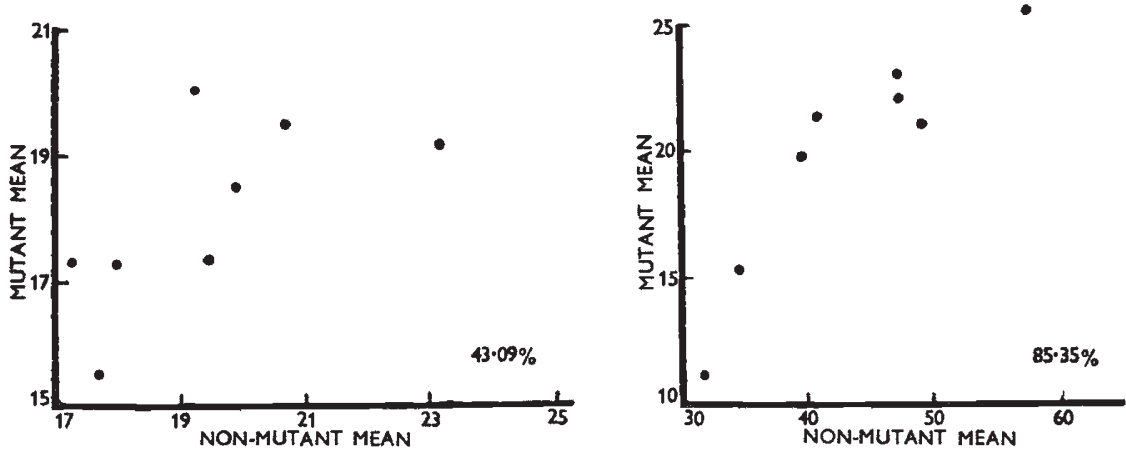

Fig. 2b.-Sternopleural chaetze. sc experiment.

FrG. 2e.-Abdominal chaetre. sc experiment.
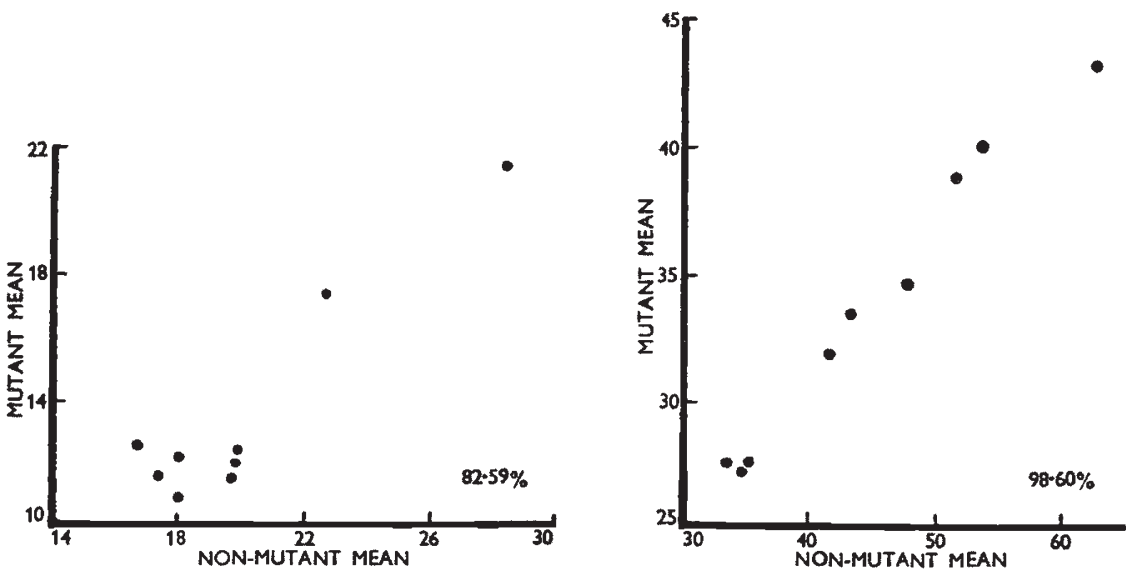

IG. 2c.-Sternopleural chaetz. $H$ experiment. Frg. $2 f$.-Abdominal chaetæ. $H$ experiment.

Frg. 2.-The relation of mean chaeta number of mutants and non-mutants. 
squares of $y$ removed by regression on $x$ ". It affords a measure of the extent of the similarity in seriation between mutant and nonmutant means.

The percentage sum of squares of mutant means removed by regression on non-mutant means is given in table 3 for sternopleural and abdominal chaeta number in each of the three experiments.

From these results it is clear that differences exist among the three mutant genes in the extent to which the polygenic systems influencing sternopleural and abdominal chaeta number in their presence differ from those operating in their non-mutant sibs, and also that the extent of the difference is not necessarily the same for the two characters. With the gene $S p$ there is close similarity between the polygenes operating in mutants and non-mutants for both characters. With the gene $H$ this similarity is shown only in respect of the abdominal

TABLE 3

Percentage sum of squares of mutant means removed by regression on non-mutant means

\begin{tabular}{|c|c|c|c|c|}
\hline & & $S p$ & $s c$ & $H$ \\
\hline Sternopleural chaetæ & . & $9^{8 \cdot 96}$ & $43 \cdot 09$ & $82 \cdot 59$ \\
\hline Abdominal chaetæ & . & $97 \cdot 17$ & $85 \cdot 35$ & $98 \cdot 60$ \\
\hline
\end{tabular}

chaetæ, there being only 82.59 per cent. correspondence of the polygenes influencing sternopleural chaeta number, while for the gene $s c$ the correspondence is even less good, 85.35 per cent. for abdominal chaetæ and only $43^{\circ} .09$ per cent. for a sternopleural chaetæ.

Figs. $2 c$ and $2 d$ suggested the possibility of a curvilinear relationship between mutant and non-mutant means in the sc experiment for both groups of chaeta. A quadratic regression was consequently fitted to each of these sets of points. In both cases an improvement of fit over the corresponding straight line was obtained, 59.75 per cent. of the sum of squares of $y$ being removed by the curved regression line for sternopleural chaetæ, $96 \cdot 72$ per cent. for abdominal chaetæ. The improvement was not significant for the sternopleurals, but was for the abdominals, giving a $\mathbf{P}$ very close to the o.o I value. The possible significance of this curvilinear relationship is considered later.

\section{(iii) Variability}

The variability of mutant and non-mutant flies was next investigated in order that the differences in variability between mutants and nonmutants could be compared with the divergence in seriation of the two groups. Where the sensitivity of the wild-type and mutant allelomorph is the same, that is, when they are equally susceptible to environmental variation, any differences in variability between 
mutants and non-mutants with the same genetic background, may be attributed to differences in the degree of balance in the operative polygenic systems, which influence the character concerned, in the two groups. If the same polygenic systems are operating, the balance established in the test lines should be reflected in the restricted variability of both mutant and non-mutant series, the extent of variability in mutants and non-mutants being similar. If different polygenes are operating, the balance of the test-lines will not be maintained in the mutant series, and they may be expected to show an increase in variability. The comparison is, however, complicated by the possibility of differences in susceptibility of the wild-type and mutant to the effects of environmental variation, such as temperature fluctuations or even to differences in the genetic background, polygenic in the present case, which may also be considered as part of the environment of the major gene in question.

As a measure of the variability of a line in respect of each of the four series of observations (sternopleural and abdominal chaeta numbers of mutants and non-mutants) the variances of the chaeta numbers of individuals round the generation means were found and combined for each series over all generations of the line from $\mathrm{B}_{5}$ onwards: the value obtained is the overall mean variance of the series. The application of Stevens' test of homogeneity (Fabergé, I936) to twelve sets of generation variances taken at random from each experiment showed there to be no significant deviation within the sets; the combination of the generation variances of a series to obtain the overall mean variance is thus permissible.

In the $S p$ and $H$ experiments it was necessary also to test the homogeneity of the male and female variances. The value of $z$ $\left(=\frac{1}{2} \log\right.$ variance ratio) was obtained from the male and female variances of the four series in each line. In finding the variance ratio the female variance was always used as numerator, the male variance as denominator, regardless of which was the larger variance ; the $z$ values thus showed negative and positive deviations from zero. To test whether the male and female variances differed significantly, the significance of the deviation of the $z$ values from zero was examined. In neither case was this significant; the male and female variances could thus be pooled in finding the overall mean variance of a series.

To obtain the overall variance, the sum of squares and number of degrees of freedom were found for each generation in any series ; from these the total sum of squares and degrees of freedom of the series were obtained. The overall variance of the series was then found from the pooled total sums of squares and degrees of freedom, from the two sexes in the case of $H$ and $S p$, from males only in the case of $s c$. The values obtained in this way are given in table 4 .

The relation between overall series variance and series mean in mutants and non-mutants is shown in the form of scatter diagrams in figs. $3 a$ to $3 f$. 
TABLE 4

Overall series variances of sternopleural and abdominal chaeta number in mutant and non-mutant fies

TABLE $4 \mathrm{~A} .-S p$ experiment

\begin{tabular}{|c|c|c|c|c|}
\hline \multirow{2}{*}{ Line } & \multicolumn{2}{|c|}{ Abdominals } & \multicolumn{2}{|c|}{ Sternopleurals } \\
\hline & Non-mutants & Mutants $(S p)$ & Non-mutants & Mutants $(S p)$ \\
\hline $\begin{array}{l}2 \\
3 \\
6 \\
7 \\
8 \\
9 \\
S k \\
O r \\
H \\
L\end{array}$ & $\begin{array}{r}5 \cdot 3786 \\
5 \cdot 9662 \\
15 \cdot 813^{8} \\
12 \cdot 0841 \\
15 \cdot 5625 \\
21 \cdot 0409 \\
7 \cdot 1134 \\
6 \cdot 69 \text { 1 } \\
7 \cdot 9961 \\
6 \cdot 3903\end{array}$ & $\begin{array}{r}6 \cdot 3200 \\
5.5693 \\
13.6515 \\
8.9901 \\
10.5016 \\
21.6519 \\
8.0291 \\
7.2717 \\
6.6502 \\
5.7410\end{array}$ & $\begin{array}{l}3 \cdot 6500 \\
1 \cdot 8263 \\
3 \cdot 1579 \\
1 \cdot 5859 \\
1 \cdot 7342 \\
3 \cdot 4305 \\
2 \cdot 6206 \\
2 \cdot 6160 \\
4 \cdot 4728 \\
1 \cdot 2777\end{array}$ & $\begin{array}{r}\mathrm{I} 1 \cdot 8354 \\
8 \cdot 6 \mathrm{I} 5 \mathrm{I} \\
8 \cdot 9500 \\
8 \cdot 3504 \\
8 \cdot 3834 \\
\mathrm{I} 1 \cdot 3474 \\
12 \cdot 1752 \\
13 \cdot 2793 \\
14 \cdot 2636 \\
5 \cdot 9607\end{array}$ \\
\hline
\end{tabular}

TABLE 4B.- $s c$ experiment

\begin{tabular}{|c|c|c|c|c|}
\hline \multirow{2}{*}{ Line } & \multicolumn{2}{|c|}{ Abdominals } & \multicolumn{2}{|c|}{ Sternopleurals } \\
\hline & Non-mutants & Mutants (sc) & Non-mutants & Mutants (sc) \\
\hline $\begin{array}{l}2 \\
3 \\
6 \\
7 \\
8 \\
9 \\
S k \\
\text { Or }\end{array}$ & $\begin{array}{r}5 \cdot 8776 \\
5 \cdot 3487 \\
14 \cdot 7060 \\
8 \cdot 1374 \\
9 \cdot 3376 \\
21 \cdot 2110 \\
5 \cdot 4705 \\
5 \cdot 4771\end{array}$ & $\begin{array}{l}2 \cdot 4671 \\
5 \cdot 75^{88} \\
6 \cdot 7405 \\
6 \cdot 5380 \\
7 \cdot 5932 \\
7 \cdot 9765 \\
3 \cdot 3696 \\
6 \cdot 738 \mathrm{r}\end{array}$ & $\begin{array}{l}4 \cdot 8978 \\
1 \cdot 9037 \\
1 \cdot 9525 \\
2 \cdot 1415 \\
1 \cdot 5916 \\
3 \cdot 4072 \\
3 \cdot 6144 \\
2 \cdot 5085\end{array}$ & $\begin{array}{l}3 \cdot 0999 \\
2 \cdot 8789 \\
3 \cdot 1108 \\
2 \cdot 6332 \\
2 \cdot 1454 \\
3 \cdot 2321 \\
1 \cdot 6152 \\
3 \cdot 0415\end{array}$ \\
\hline
\end{tabular}

TABLE 4C. $-H$ experiment

\begin{tabular}{|c|c|c|c|c|}
\hline \multirow{2}{*}{ Line } & \multicolumn{2}{|c|}{ Abdominals } & \multicolumn{2}{|c|}{ Sternopleurals } \\
\hline & Non-mutants & Mutants $(H)$ & Non-mutants & Mutants $(H)$ \\
\hline $\begin{array}{l}2 \\
3 \\
6 \\
7 \\
8 \\
9 \\
O r \\
H \\
L\end{array}$ & $\begin{array}{r}6 \cdot 0264 \\
4 \cdot 8972 \\
25 \cdot 9468 \\
11 \cdot 9944 \\
12 \cdot 4787 \\
26 \cdot 3231 \\
6 \cdot 4278 \\
6 \cdot 9977 \\
6 \cdot 8541\end{array}$ & $\begin{array}{r}7 \cdot 3616 \\
4 \cdot 7296 \\
9 \cdot 2623 \\
6 \cdot 8102 \\
6 \cdot 4241 \\
11 \cdot 6750 \\
7 \cdot 0778 \\
4 \cdot 2188 \\
3 \cdot 7392\end{array}$ & $\begin{array}{l}3 \cdot 5035 \\
I \cdot 9398 \\
2 \cdot 6942 \\
I \cdot 5455 \\
I \cdot 1935 \\
2 \cdot 3537 \\
1 \cdot 8899 \\
5 \cdot 6774 \\
1 \cdot 2731\end{array}$ & $\begin{array}{l}3 \cdot 27 \text { I } 5 \\
2 \cdot 96 \text { I } 1 \\
3 \cdot 3149 \\
3 \cdot 3000 \\
4 \cdot 1944 \\
4 \cdot 3296 \\
3 \cdot 9400 \\
3 \cdot 1063 \\
2 \cdot 5257\end{array}$ \\
\hline
\end{tabular}




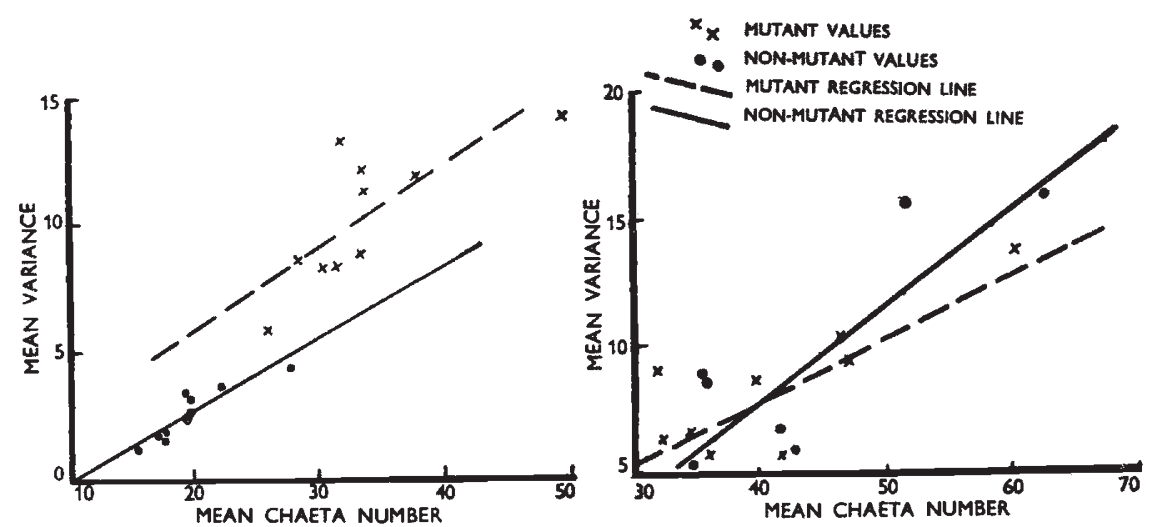

FIG. 3a.-Sternopleural chaetz. Sp experiment. FIG. 3d.-Abdominal chaetz. Sp experiment.

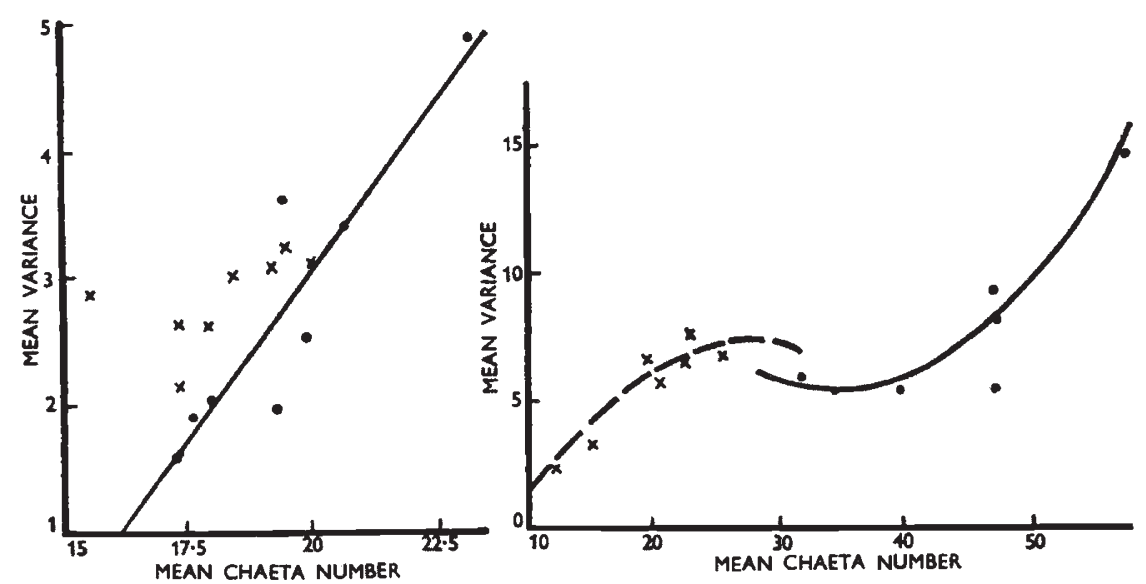

FIG. 3b.-Sternopleural chaetæ. sc experiment. FIG. 3e.-Abdominal chaetæ. sc experiment.
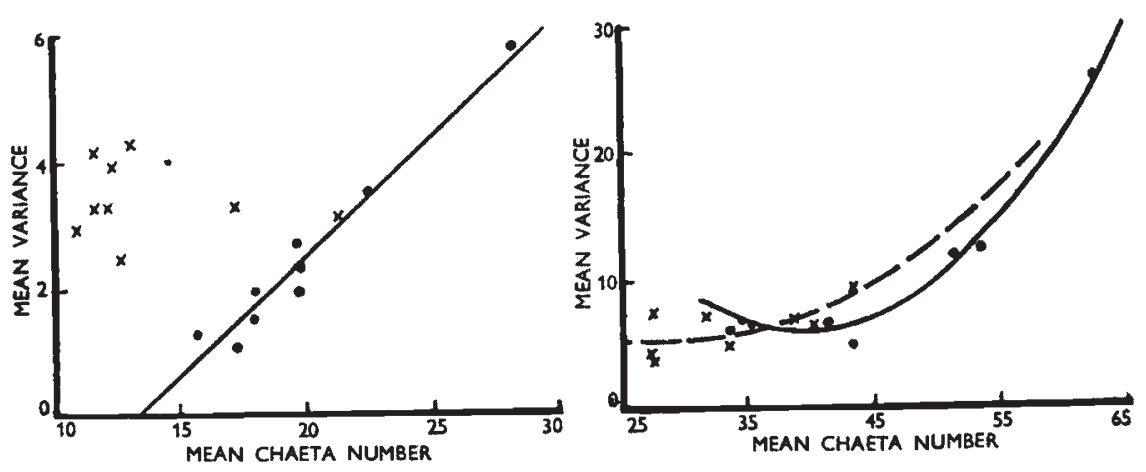

FIG. $3 c$.-Sternopleural chaetæ. $H$ experiment. FIG. $3 f$.-Abdominal chaetæ. $H$ experiment.

FIG. 3.-The relation of mean variance to mean chaeta number in mutants and non-mutants. 
In considering the variability of abdominal chaeta number, line 9 was omitted, since the " between generations" variability of abdominal chaeta number in the non-mutant series of line 9 was found to be significantly greater than that for the other lines. This was not true for the variability of sternopleural chaeta number ; line 9 was therefore included when considering this character.

The variability of the lines for the non-mutant series, as measured by the overall variance, increased as the mean chaeta number increased. Since the mutant means frequently differed from the non-mutant means, a straightforward comparison of the variances of the two groups could not be expected to give the information required, for account must be taken of the effects of such differences on the measure of variation. Two methods were used to achieve this end, firstly the

TABLE 5

Comparison of the coefficients of variability of mutant and non-mutant series

\begin{tabular}{|c|c|c|c|c|c|c|}
\hline & & \multicolumn{2}{|c|}{$\begin{array}{l}\text { Mean coefficient } \\
\text { of variability }\end{array}$} & \multirow{2}{*}{$t$} & \multirow{2}{*}{$\mathbf{N}$} & \multirow{2}{*}{$\mathbf{P}$} \\
\hline & & Non-mutant & Mutant & & & \\
\hline $\begin{array}{l}\text { Sternopleural } \\
\text { chaetæ }\end{array}$ & $\left\{\begin{array}{l}S p \\
H \\
s c\end{array}\right.$ & $\begin{array}{l}0 \cdot 1300 \\
0 \cdot 1170 \\
0 \cdot 1382\end{array}$ & $\begin{array}{l}0.3067 \\
0.2642 \\
0.1502\end{array}$ & $\begin{array}{l}8 \cdot 6870 \\
5.3083 \\
0.6090\end{array}$ & $\begin{array}{l}18 \\
16 \\
14\end{array}$ & $\begin{array}{l}<0.001 \\
<0.001 \\
0.5 \cdot 0.7\end{array}$ \\
\hline $\begin{array}{l}\text { Abdominal } \\
\text { chaetze }\end{array}$ & $\left\{\begin{array}{l}S p \\
H \\
s c\end{array}\right.$ & $\begin{array}{l}0 \cdot 2046 \\
0 \cdot 2148 \\
0 \cdot 1764\end{array}$ & $\begin{array}{l}0 \cdot 1955 \\
0 \cdot 1836 \\
0 \cdot 2797\end{array}$ & $\begin{array}{l}0.4289 \\
0.88 \mathrm{rI} \\
4.2313\end{array}$ & $\begin{array}{l}16 \\
14 \\
12\end{array}$ & $\begin{array}{c}0.5-0.7 \\
0.3-0.5 \\
0.01-0 \cdot 001\end{array}$ \\
\hline
\end{tabular}

comparison of the coefficient of variability in corresponding mutant and non-mutant series, and secondly the method of co-variance analysis.

The coefficient of variability as measured by $\frac{\text { mean variance }}{\text { mean }}$ was found for all the lines in both mutant and non-mutant series in each experiment, and the mean coefficient of variability for each series computed. The coefficients of variability of corresponding mutant and non-mutant series were compared using a $t$ test. The coefficients of variability and the values of $t$ and $\mathrm{P}$ obtained are given in table 5 .

It will be seen that this method brings out significant increases in variability of mutant over non-mutant in three cases-for sternopleural chaeta number in $S p$ and $H$ mutants, and for abdominal chaetæ in sc mutants.

The method of co-variance analysis consists essentially in testing whether each set of mutant points shown in figs. $3^{a}$ to $3 f$ could be assumed to lie on the same regression line as the corresponding set of non-mutant points. 
In carrying out a co-variance analysis it is not necessary actually to find the best-fitting regression lines for the mutant and non-mutant values; these were, however, computed and included in figs. $3^{a}$ to $3 f$ to permit visual comparison of the two corresponding lines. For the data on sternopleural chaeta number in the three experiments a linear regression appeared, from the graphs, to give an adequate fit for the non-mutant values, and it was not considered necessary to use a regression of higher order. The regression of variance on mean was found to be not significant for the mutant data in the $H$ and sc flies ; the regression lines for these data are consequently not given. The regression was, however, significant for the $S p$ mutant data, and the regression line for these data is included in fig. $3 a$. Inspection of figs. $3^{d}, 3^{e}$ and $3 f$, showing the relation of variance and mean for abdominal chaeta number, suggested that a quadratic regression line would give a better fit to the data than the linear; both regressions were therefore computed. The quadratic regression was found to give a significant improvement in fit for the non-mutant data of the $H$ and $s c$ experiment and was used in preference to the linear regression. The improvement in fit for the non-mutant data of the $S p$ experiment was not significant ; the linear regression was therefore used.

In carrying out a co-variance analysis the two sets of data are pooled. From the pooled data the total and between-series sums of squares of variance and mean, and the sums of cross-products of variance and mean are computed. The difference between the two gives the within series values. A correction for regression is applied to the total and within series sums of squares for variances, removing that amount of the sums of squares attributable to regression on the mean. This correction takes up one degree of freedom where based on a linear regression, two where based on a quadratic regression. An analysis of variance is then carried out for the variance values, using the corrected total and within series sums of squares, the difference between them being the corrected between-series sum of squares. The mean squares between and within series can be compared by a $t$, found as the square root of the $\frac{\text { mean square between series }}{\text { mean square within series }}$. The number of degrees of freedom for $t$ will be that of the within series item. The probability of the value of $t$ obtained will show whether or not the difference between the data of the two series is significantly large (Mather, $1943 a$ ).

The values of $t$ and $\mathbf{P}$ found in this way are given in table 6 .

The method of co-variance analysis brings out significant differences between mutants and non-mutants in the variability of sternopleural chaeta number in both the $S p$ and $H$ experiments and of abdominal chaeta number in the sc experiment (as did the comparison of the coefficients of variability in the two groups).

For abdominal chaeta number in the $H$ and $S p$ experiments, over 97 per cent. correspondence in seriation of non-mutant and 
mutant means was found. The comparison of the variances of the two groups shows that the variability of abdominal chaeta number in the $H$ and $S p$ mutants is closely similar to that in the related nonmutants. In these two cases where the operative polygenic systems are similar in mutants and non-mutants, the extent of variability is, as expected, also similar.

For sternopleural chaeta number in the $S p$ experiment, where correspondence in seriation was almost 99 per cent., a significant difference in variability between mutants and non-mutants was found, there being a marked increase in variability in mutant flies. It can be seen from fig. $3 a$ that this difference in variability is due almost entirely to the difference in the value of the mean for the two regressions relating variance to mean chaeta number. The direction of slope of the mutant and non-mutant regression lines is almost parallel. The regression coefficients measuring the direction

TABLE 6

Comparison of the variability of mutant and non-mutant series

\begin{tabular}{|c|c|c|c|c|}
\hline & & $S p$ & $s c$ & $H$ \\
\hline $\begin{array}{l}\text { Sternopleural } \\
\text { chaeta number }\end{array}$ & $\stackrel{t}{\mathrm{P}}$ & $\begin{array}{c}3.12(17) \\
0.01-0.001\end{array}$ & $\begin{array}{l}1 \cdot 65(13) \\
0 \cdot 1-0 \cdot 2\end{array}$ & $\begin{array}{c}3.80(15) \\
0.01-0.001\end{array}$ \\
\hline $\begin{array}{l}\text { Abdominal } \\
\text { chaeta number }\end{array}$ & $\stackrel{t}{\mathrm{P}}$ & $\begin{array}{c}0.3^{8(15)} \\
0.7-0.8\end{array}$ & $\begin{array}{c}3.83(10) \\
0.01-0.001\end{array}$ & $\begin{array}{c}0.19(12) \\
0.8-0.9\end{array}$ \\
\hline
\end{tabular}

Numbers in brackets refer to the degrees of freedom on which $t$ is based.

of slope for the two lines were not significantly different, the nonmutant regression coefficient $b^{\prime}$ being $0 \cdot 2830 \pm 0 \cdot 0469$, and the mutant regression coefficient $b^{\prime \prime}$ being $0 \cdot 3096 \pm 0 \cdot 0976$. This parallelism in the two regression lines, together with the close correspondence in the seriation of the means in mutants and non-mutants, suggests that the increase in variability is due not to the disruption of balance in mutant flies but to the greater sensitivity of the mutant phenotype to environmental fluctuations as compared with the wild-type phenotype. Since the major mutant is the same in all the lines, such an increase in variability would be expected to be of the same extent throughout, resulting in the parallel regression lines for mutants and non-mutants, as found here. The degree of expression of the mutant gene $S p$ is reported by Bridges and Brehme (1944) to be markedly influenced by temperature, the phenotype being identical with wildtype at $19^{\circ} \mathrm{C}$., the degree of expression of the gene increasing as the temperature increases, at $25^{\circ} \mathrm{C}$. as found in this experiment, the sternopleural chaetæe being almost double that of wild-type flies. The increase in variability in $S p$ flies then is most probably due to the 
sensitivity of the $S p$ allelomorph to slight temperature differences within the culture bottle or to fluctuations in temperature in the incubator during the course of development of the flies.

Considering next those data for which more marked differences in seriation were observed, it can be seen from table 6 that in two cases, sternopleural chaeta number in the $H$ experiment, with 83 per cent. correspondence in seriation of the means, and abdominal chaeta number in the sc experiment, with 85 per cent. correspondence, marked differences in variability in mutant and non-mutant flies were found. In the case of sternopleural chaeta number in the $s c$ experiment, however, where there was only 43 per cent. correspondence in seriation of mutant and non-mutant means, co-variance analysis

TABLE 7

Summary of results

\begin{tabular}{|c|c|c|c|c|}
\hline Gene & Character & $\begin{array}{c}\text { Average } \\
\text { change in } \\
\text { mean chaeta } \\
\text { number }\end{array}$ & $\begin{array}{l}\text { Per cent. } \\
\text { correspondence } \\
\text { in seriation } \\
\text { of mutants } \\
\text { and non-mutants }\end{array}$ & Effect on variability \\
\hline \multirow{2}{*}{$S p$} & Sternopleural & +13.84 & $98 \cdot 96$ & Increased. Relation to mean \\
\hline & $\begin{array}{l}\text { Abdominal } \\
\text { chaet }\end{array}$ & $-2 \cdot 36$ & $97 \cdot 17$ & Unchanged \\
\hline \multirow{2}{*}{$s c$} & $\begin{array}{l}\text { Sternopleural } \\
\text { chaetæ }\end{array}$ & $-1 \cdot 36$ & $43 \cdot 09$ & $\begin{array}{l}\text { Not increased. Relation to } \\
\text { mean changed? }\end{array}$ \\
\hline & $\begin{array}{l}\text { Abdominal } \\
\text { chaetæ }\end{array}$ & $-23 \cdot 76$ & $85 \cdot 35$ & $\begin{array}{c}\text { Increased. Relation to mean } \\
\text { changed }\end{array}$ \\
\hline \multirow{2}{*}{$H$} & $\begin{array}{l}\text { Sternopleural } \\
\text { chaetæ }\end{array}$ & $-6 \cdot 12$ & $82 \cdot 59$ & $\begin{array}{l}\text { Increased. Relation to mean } \\
\text { changed }\end{array}$ \\
\hline & $\begin{array}{l}\text { Abdominal } \\
\text { chaetæ }\end{array}$ & $-I I \cdot I I$ & $98 \cdot 60$ & Unchanged \\
\hline
\end{tabular}

did not reveal any differences in variability between the two groups. It may be remembered, however, that the regression of variance on mean was not significant, while that for the non-mutant values was markedly so, indicating that, although a common regression line can be fitted to the two sets of data, there is nevertheless a difference in the relation of variability to mean in the two groups.

\section{DISCUSSION}

To facilitate discussion the results are summarised in table 7 , where the gross effects of the three mutant genes on chaeta numbers, their effects on seriation and on variability are recorded.

The seriation of means of $S p$ individuals was found to be closely similar to that of non-mutants for both sternopleural and abdominal chaetæ. It may consequently be assumed that the polygenic systems 
influencing these characters in the mutants are very similar to those operative in non-mutants. For the other two major genes, such a close correspondence in seriation for the two characters was not obtained ; in $H$ flies the seriation was similar between mutants and non-mutants for abdominal chaetæ but not for sternopleural chaetæ. The polygenic system influencing sternopleural chaeta number in non-mutants is disturbed to a greater extent by the presence of $H$ than is that for abdominal chaeta number. This is true with sc also, though with this gene the divergence of the polygenic systems for both characters, from that operative in non-mutants, is more marked than with the other two genes.

The extent of the divergence of the polygenic systems of mutants from those operative in non-mutants thus differs for the three major genes investigated, and in any one mutant group may differ also for the two characters, sternopleural and abdominal chaeta numbers.

While any deviation from linear relationship of mutant and nonmutant means indicates divergence in the operative polygenic systems, it cannot be determined from the available evidence whether this divergence results from differences in the mode of action in the mutant flies, of polygenes operative in non-mutants, or from the activity of newly-evoked polygenes in mutant individuals, which in the absence of the mutant allelomorph, had no differential effect upon the two characters observed. In one instance the results indicate the former to be the case. For abdominal chaetæ in $s c$ individuals the line means show a close curvilinear relation $(96 \cdot 72$ per cent. correspondence) with those in non-mutants; there is no reason to expect any such relation where new polygenes are active-rather it would seem that, in this case, the operative polygenic system is similar in the two groups but that the presence of $s c$ imposes a limitation on its activity in the lines with higher chaeta number, restricting the full activity of the members of the system making for higher chaeta number.

The polygenes investigated may be considered to be acting as modifiers, affecting the manifestation of the characters sternopleural and abdominal chaeta number. Certain of the polygenes have been shown to be operative in the same way in the mutant and non-mutant groups; these are non-specific modifiers affecting the manifestation of the character in the presence of both wild-type and mutant allelomorphs of the major genes. Others appear to be specific modifiers, operating only in mutant or non-mutant individuals or having a different action in the two. Similar specific modifiers have been demonstrated by Fisher and Holt (1944) in the mouse. They were investigating the selective modification of the expression of the gene $S d$, causing short tail in the heterozygous state, taillessness and early death when homozygous. By selection for increased length of tail in heterozygous $S d$ mice, a difference of over $30 \mathrm{~mm}$. in tail length was obtained between the longer- and shorter-tailed mice. It was 
found, however, that tail length in the homozygous non-mutant progeny was almost exactly the same in both selection lines. The modifiers having such a marked effect on tail length in the presence of the mutant allelomorph were without effect in the normal tailed mice.

Comparison of columns 3 and 4 of table 7 shows that the extent of divergence in seriation in mutants from that of non-mutants is not correlated with the magnitude of the gross effect on the mean of the mutant gene. Of particular interest are the two cases in which the mutant gene has a drastic effect on the character while leaving the seriation of the line means almost unaffected, namely, sternopleural chaeta number in $S p$ flies and abdominal chaeta number in $H$ flies. The action of a major gene has been compared with that of a switch mechanism, diverting the development of the organism into one or other of the available paths, the polygenes acting as buffering genes determining the direction and precision of the developmental path taken (Mather, I $943^{b}$ ). Here then it would seem that the paths into which the development of the chaetæ is switched by the two major mutants result in marked differences from non-mutant individuals. But the polygenes delimiting the developmental paths in mutants and non-mutants are similar. Two alternatives are presented, either that the divergence of the developmental paths resulting from the action of the majos mutants occurs late in development, much of the polygenic adjustment of the character occurring prior to this, or, if the major genes are presumed to act early in development, that many of the operative polygenes are common to the divergent paths followed in mutant and non-mutant individuals. Of these two alternatives, the latter would seem to be the more acceptable, since it is unlikely that so much of the fine adjustment of a char acter would occur prior to the action of genes of such drastic effect as $H$ and $S p$.

Mutant $S p$ individuals exhibit little difference in respect of abdominal chaetæ from their non-mutant sibs in either mean chaeta number, seriation of the means or variability. The slight reduction in mean chaeta number in $S p$ flies has probably resulted not from the direct effect of the major mutant itself but of polygenes closely linked with this locus. The evidence does not permit a decision to be made between these two alternatives, though there is some indication from line 3 that closely linked polygenes are responsible, since in several generations of this line the mutant individuals had a mean abdominal chaeta number equal to or above that of the non-mutants. This would be expected if a rare recombination very close to the $S p$ locus had occurred here, eliminating the closely-linked minus polygenes from this line. Since $S p$ affects sternopleurals markedly and abdominals only very slightly or more probably not at all, this gene must act at least sufficiently late in development for the two hair characters to have diverged. 
It might be expected that between two characters as similar as sternopleural and abdominal chaeta number some obvious developmental relationship would exist, in the nature of a simple positive correlation between the two characters, both depending on the general chaeta-producing capacity of the fly, the expression of the two increasing or decreasing simultaneously, or a simple negative correlation, as would be found if there were a limited capacity for chaeta production, increase in one character resulting in a decrease in the other (Mather and Harrison, 1949).

Consideration of the gross effects of the three major mutants investigated on each of the two characters indicates that their relationship is by no means so simple. It should particularly be noticed that the mutant $S p$, while resulting in a marked increase in sternopleural chaeta number, has only a very slight or possibly no effect on abdominal chaetæ. While they are less striking, differences in the magnitude of the effect on the two characters of the other two major genes investigated were also found. If the developmental path were much the same for the two characters, the effect of a gene on each would be expected to be similar. The observed differences in effect of each of the three major genes on sternopleural and abdominal chaetæ suggest therefore a divergence of the developmental paths of the two characters.

The differences in sternopleural chaeta number among several of the lines used had originated as a result of correlated response to selection applied to the abdominal chaetæ. Such correlated responses may be due either to pleiotropy in action of the polygenes affecting the two characters simultaneously or to linkage of the members of two distinct polygenic systems. The results of Mather and Harrison (1949) suggested that though correlated response of sternopleural and abdominal chaetæ may result in part from a physiological relation of the two characters and pleiotropy of the effective polygenes, linkage was in part responsible, though perhaps to a lesser extent. The results of the present experiments provide some further evidence on this point. The extent of the divergence of the operative polygenic systems of mutants and non-mutants differed for the two characters in the sc and $H$ experiments. That the polygenic systems controlling the two characters are affected differently by these two major genes shows that the systems must be distinct at least in part. This is supported indirectly by the difference in the gross effects of the major gene $S p$ on the two characters, for if this gene may affect one character while having little or no effect on the other, this suggests that polygenes similarly may affect only one of the two characters.

Where the polygenic systems controlling the expression of a character are very similar in mutant and non-mutant individuals, as tested by seriation, the variability of the character, in so far as it depends on the degree of balance in the operative polygenic system, will also be expected to be similar in the two groups. Such a similarity 
was found in two cases in which similarity in the operative polygenes controlling chaeta number had been demonstrated (for abdominals in the $S p$ and $H$ experiments). In a third case (sternopleurals in the $S p$ experiment) there was a considerable increase in variability of the character in mutant individuals, but it should be noted that although there was here a general increase in variability throughout all the tested lines, the relation of variability to mean chaeta number remained unchanged. Where tests of seriation showed the polygenic systems of the mutants to diverge from those operative in non-mutants: the relation of variability to mean chaeta number was found to be different in the two classes, though this is not clearly brought out with scute. A significant increase in variability was found in two cases only, for sternopleurals in $H$ individuals and for abdominals in $s c$ individuals. The particular relation of variability to mean chaeta number seems then to be a property of the particular polygenic system in action, since where the polygenic systems influencing a character are similar in two groups the relation of variability to mean is similar, while where the operative polygenic systems differ the relation of variability to mean also differs.

\section{SUMMARY}

(I) Three major mutant genes affecting chaeta number were introduced by back-crossing into ten wild-type lines of Drosophila melanogaster having different mean numbers of sternopleural and abdominal chaetæ. The chaetæ of mutant and non-mutant flies were counted in each generation, and the counts combined to obtain the line means.

(2) The extent of correspondence in order of magnitude or seriation of the mutant and non-mutant means indicates the degree of similarity between the operative polygenic systems of the two groups.

(3) The degree of correspondence in seriation of the line means between non-mutants and mutants with the genes $S p, s c$ and $H$ was, for abdominal chaetæ, $97 \cdot 17,85.35$ and $98 \cdot 60$ per cent., and for sternopleural chaetæ $98 \cdot 96,43 \cdot 09$ and $82 \cdot 59$ per cent. respectively.

(4) Thus the extent of similarity in the operative polygenic systems of mutants and non-mutants differs for the different major genes and may differ also for two characters affected by the same major gene. Furthermore, the polygenic systems controlling abdominal and sternopleural chaeta number are distinct at least in part.

(5) The extent of divergence of the operative polygenic systems of mutants and non-mutants was not correlated with the magnitude of the gross effect of the mutant gene.

(6) The variabilities of the two characters were similar in mutants and non-mutants where seriation indicated that the operative polygenic 
systems were similar, except in one case where the mutant phenotype is highly sensitive to environmental differences.

Acknowledgments.-I am greatly indebted to Professor K. Mather and Mr L. G. Wigan for their advice and encouragement throughout this research. The work was supported by a grant from the Department of Scientific and Industrial Research and was executed at the Department of Genetics, University of Birmingham.

\section{REFERENCES}

BARTLETT, M. S., AND HALDANE, J. B. S. I 935 . The theory of inbreeding with forced heterozygosis. 7. Genet., 31, 327-340.

BRIDGES, C. B., AND BREHME, K. S. 1944. The mutants of Drosophila melanogaster. Carnegie Instn., Wash. Publ., 552.

FABERGE, A. c. I 936 . The physiological consequences of polyploidy. F. Genet., 33. Appendix, 398-399.

FISHER, R. A., AND HOLT, S. B. I944. The experimental modification of dominance in Danforth's short-tailed mutant mice. Ann. Eugen., Lond., I2, I 02-1 20.

HASKELL, G. M. L. I943. The polygenes affecting the manifestation of scute in Drosophila melanogaster. 7. Genet., 45, 269-276.

MATHER, K. 1942. The balance of polygenic combinations. 7. Genet., 43, 309-336. MATHER, K. I943a. Statistical Analysis in Biology. London: Methuen.

MATHER, K. 1943b. Polygenic balance in the canalization of development. Nature, I5I, 68-7I.

MATHER, K., AND harRison, B. J. 1949. The manifold effects of selection. Heredity, 3, I-52. 